\title{
On New Generalized Ostrowski Type Integral Inequalities
}

\author{
A. Qayyum, ${ }^{1}$ M. Shoaib, ${ }^{2}$ A. E. Matouk, ${ }^{2}$ and M. A. Latif ${ }^{3}$ \\ ${ }^{1}$ Department of Fundamental and Applied Sciences, Universiti Teknologi Petronas, Bandar Seri Iskandar, \\ 31750 Tronoh, Perak, Malaysia \\ ${ }^{2}$ Department of Mathematics, University of Ha’il, P.O. Box 2440, Ha'il 81451, Saudi Arabia \\ ${ }^{3}$ School of Computational and Applied Mathematics, University of the Witwatersrand (Wits), Private Bag 3, \\ Johannesburg 2050, South Africa
}

Correspondence should be addressed to A. Qayyum; atherqayyum@gmail.com

Received 26 February 2014; Revised 30 March 2014; Accepted 6 May 2014; Published 22 May 2014

Academic Editor: Elena Berdysheva

Copyright (C) 2014 A. Qayyum et al. This is an open access article distributed under the Creative Commons Attribution License, which permits unrestricted use, distribution, and reproduction in any medium, provided the original work is properly cited.

\begin{abstract}
The Ostrowski inequality expresses bounds on the deviation of a function from its integral mean. The aim of this paper is to establish some new inequalities similar to the Ostrowski's inequality. The current paper obtains bounds for the deviation of a function from a combination of integral means over the end intervals covering the entire interval in terms of the norms of the second derivative of the function. Some new perturbed results are obtained. Application for cumulative distribution function is also discussed.
\end{abstract}

\section{Introduction}

Ostrowski [1] proved his famous inequality in 1938. Milovanović and Pecarić gave the first generalization of Ostrowski's inequality [2]. A number of Ostrowski type inequalities have been derived by Cerone [3], Cheng [4], Dragomir and Barnett [5], Sofo and Dragomir [6], Milovanović [7], and G. V. Milovanović and I. Z. Milovanović [8] with applications in numerical analysis and probability. Several further generalizations are provided by Hussain and Qayyum [9], Qayyum and Hussain [10], and Pecarić [11], respectively. More recent results concerning the generalizations of Ostrowski inequality are given by $[4,5,12,13]$. Dragomir and Wang [14] combined Ostrowski and Grüss inequality to give a new inequality which they named Ostrowski-Grüss type inequality. Cheng gave a sharp version of Ostrowski-Grüss inequality in [4]. Cerone [3] and Dragomir and Wang in [14-17] obtained bounds on a particular quadrature rule for differentiable functions which we generalize to two times differentiable functions. This generalization improves bounds on the deviation of a function from a combination of integral means. Some new perturbed results are also discussed. The generalized inequalities obtained in this paper will have applications in approximation theory, probability theory, and numerical analysis. We will show an application of the inequalities obtained for cumulative distribution function.

In this paper, we will use the usual $L_{p}$ norms $\|k\|_{p}$ defined for a function $k \in L_{p}[a, b]$ as follows:

$$
\begin{gathered}
\|k\|_{\infty}:=\text { ess } \sup _{t \in[a, b]}|k(t)|, \\
\|k\|_{p}:=\left(\int_{a}^{b}|k(t)|^{p} d t\right)^{1 / p}, \quad 1 \leq p<\infty .
\end{gathered}
$$

Let $S(f ; a, b)$ be defined by

$$
S(f ; a, b):=f(x)-M(f ; a, b),
$$

where

$$
M(f ; a, b):=\frac{1}{b-a} \int_{a}^{b} f(x) d x
$$

is the integral mean of $f$ over $[a, b]$. The functional $S(f ; a, b)$ represents the deviation of $f(x)$ from its integral mean over $[a, b]$.

Ostrowski [1] proved the following interesting and useful integral inequality. 
Theorem 1. Let $f:[a, b] \rightarrow \mathbb{R}$ be continuous on $[a, b]$ and differentiable on $(a, b)$, whose derivative $f^{\prime}:(a, b) \rightarrow \mathbb{R}$ is bounded on $(a, b)$ by a constant $M$. Then,

$$
|S(f ; a, b)| \leq\left[\left(\frac{b-a}{2}\right)^{2}+\left(x-\frac{a+b}{2}\right)^{2}\right] \frac{M}{b-a},
$$

for all $x \in[a, b]$.

In a series of papers, Dragomir and Wang [14-17] proved (4) and some of its variants for $f^{\prime} \in L_{p}[a, b]$, when $p \geq 1$, making use of a Peano kernel and Montgomery's identity [18]. Montgomery's identity states that for absolutely continuous mappings $f:[a, b] \rightarrow \mathbb{R}$

$$
f(x)=\frac{1}{b-a} \int_{a}^{b} f(t) d t+\frac{1}{b-a} \int_{a}^{b} P(x, t) f^{\prime}(t) d t,
$$

where the kernel $P:[a, b]^{2} \rightarrow \mathbb{R}$ is given by

$$
P(x, t):= \begin{cases}t-a, & \text { if } a \leq t \leq x \leq b, \\ t-b, & \text { if } a \leq x<t \leq b .\end{cases}
$$

If we assume that $f^{\prime} \in L_{\infty}[a, b]$, then $M$ in (4) may be replaced by $\left\|f^{\prime}\right\|_{\infty}$.

Dragomir and Wang [14-17], utilizing an integration by parts argument, obtained

$$
\begin{aligned}
& |S(f ; a, b)| \\
& \leq\left\{\begin{array}{c}
\frac{1}{b-a}\left[\left(\frac{b-a}{2}\right)^{2}+\left(x-\frac{a+b}{2}\right)^{2}\right]\left\|f^{\prime}\right\|_{\infty}, \\
f^{\prime} \in L_{\infty}[a, b], \\
\frac{1}{b-a}\left[\frac{(x-a)^{q+1}+(b-x)^{q+1}}{q+1}\right]^{1 / q}\left\|f^{\prime}\right\|_{p^{\prime}} \\
\frac{f^{\prime} \in L_{p}[a, b], p>1, \frac{1}{p}+\frac{1}{q}=1,}{b-a}\left[\frac{b-a}{2}+\left|x-\frac{a+b}{2}\right|\right]\left\|f^{\prime}\right\|_{1}, \\
f^{\prime} \in L_{1}[a, b],
\end{array}\right.
\end{aligned}
$$

where $f:[a, b] \rightarrow \mathbb{R}$ is absolutely continuous on $[a, b]$ and the constants $1 / 4,[1 /(q+1)]^{1 / q}$, and $1 / 2$ are sharp.

Cerone [3] proved the following inequality.

Theorem 2. Let $f:[a, b] \rightarrow \mathbb{R}$ be absolutely continuous. Define

$$
\tau(x ; \alpha, \beta):=f(x)-\frac{1}{\alpha+\beta}[\alpha M(f ; a, x)+\beta M(f ; x, b)] .
$$

Then,

$$
\begin{aligned}
& |\tau(x ; \alpha, \beta)|
\end{aligned}
$$

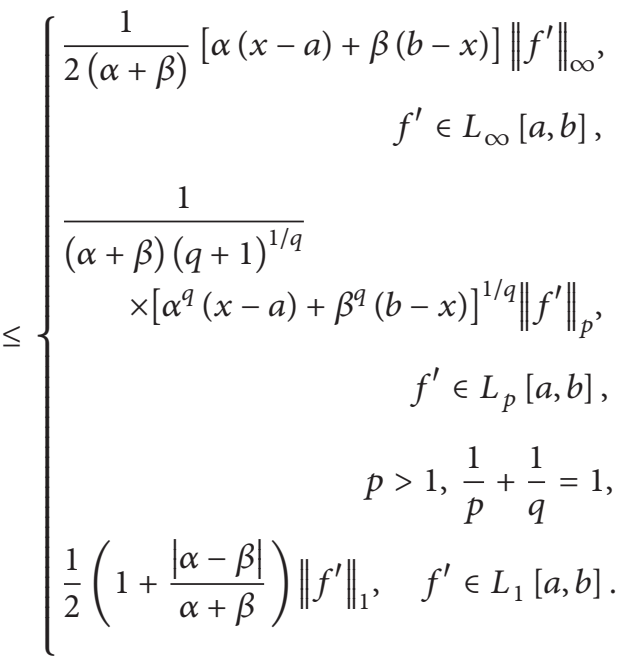

In [19], Pachpatte established Čebyŝev type inequalities by using Pecarić's extension of the Montgomery identity [18]. The current paper obtains bounds on the deviation of a function from integral means from the end of the interval which cover the whole interval, in terms of the norms of the second derivative of the function. The paper closely follows ideas from [3], where corresponding results were proved using bounds in terms of the first derivative of the function.

\section{Main Results}

Denote by $P(x, \cdot):[a, b] \rightarrow \mathbb{R}$ the kernel given by

$$
P(x, t):= \begin{cases}\frac{\alpha}{\alpha+\beta} \frac{1}{x-a} \frac{(t-a)^{2}}{2}, & a \leq t \leq x, \\ \frac{\beta}{\alpha+\beta} \frac{1}{b-x} \frac{(t-b)^{2}}{2}, & x<t \leq b,\end{cases}
$$

where $\alpha, \beta \in \mathbb{R}$ are nonnegative and not both zero.

Before we state and prove our main result, we will prove the following identity, which will be used to obtain bounds.

Lemma 3. Let $f:[a, b] \rightarrow \mathbb{R}$ be two times differentiable on $[a, b]$. Then,

$$
\begin{aligned}
\int_{a}^{b} P(x, t) f^{\prime \prime}(t) d t & \\
= & \frac{1}{2(\alpha+\beta)}[\alpha(x-a)-\beta(b-x)] f^{\prime}(x)-f(x) \\
& \quad+\frac{1}{\alpha+\beta}\left[\frac{\alpha}{x-a} \int_{a}^{x} f(t) d t+\frac{\beta}{b-x} \int_{x}^{b} f(t) d t\right] .
\end{aligned}
$$

Proof. From (10), we have

$$
\begin{aligned}
\int_{a}^{b} P & (x, t) f^{\prime \prime}(t) d t \\
& =\frac{\alpha}{(\alpha+\beta)} \frac{1}{x-a} \int_{a}^{x} \frac{(t-a)^{2}}{2} f^{\prime \prime}(t) d t
\end{aligned}
$$




$$
\begin{aligned}
& +\frac{\beta}{(\alpha+\beta)} \frac{1}{b-x} \int_{x}^{b} \frac{(t-b)^{2}}{2} f^{\prime \prime}(t) d t \\
= & \frac{\alpha}{2(\alpha+\beta)} \frac{1}{x-a} \\
& \times\left[(x-a)^{2} f^{\prime}(x)-2 \int_{a}^{x}(t-a) f^{\prime}(t) d t\right] \\
& +\frac{\beta}{2(\alpha+\beta)} \frac{1}{b-x} \\
& \times\left[-(x-b)^{2} f^{\prime}(x)-2 \int_{x}^{b}(t-b) f^{\prime}(t) d t\right] .
\end{aligned}
$$

After further simplification, we get the required identity (11).

We now give our main result.

Theorem 4. Let $f:[a, b] \rightarrow \mathbb{R}$ be a two times differentiable function. Define

$$
\begin{aligned}
\tau(x ; \alpha, \beta):= & \frac{1}{2(\alpha+\beta)}[\alpha(x-a)-\beta(b-x)] f^{\prime}(x)-f(x) \\
& +\frac{1}{\alpha+\beta}[\alpha M(f ; a, x)+\beta M(f ; x, b)],
\end{aligned}
$$

where $M(f ; a, b)$ is the integral mean defined in (3). Then,

$$
\begin{aligned}
& |\tau(x ; \alpha, \beta)| \\
& \quad \leq\left\{\begin{array}{l}
{\left[\alpha(x-a)^{2}+\beta(b-x)^{2}\right] \frac{\left\|f^{\prime \prime}\right\|_{\infty}}{6(\alpha+\beta)}} \\
f^{\prime \prime} \in L_{\infty}[a, b] \\
(2 q+1)^{1 / q} \\
\times\left[\alpha^{q}(x-a)^{q+1}+\beta^{q}(b-x)^{q+1}\right]^{1 / q} \frac{\left\|f^{\prime \prime}\right\|_{p}}{2(\alpha+\beta)} \\
\quad f^{\prime \prime} \in L_{p}[a, b] \\
\quad p>1, \frac{1}{p}+\frac{1}{q}=1, \\
(\alpha(x-a)+\beta(b-x)+|\alpha(x-a)-\beta(b-x)|) \\
\times \frac{\left\|f^{\prime \prime}\right\|_{1}}{4(\alpha+\beta)}, \quad f^{\prime \prime} \in L_{1}[a, b],
\end{array}\right.
\end{aligned}
$$

for all $x \in[a, b]$.
Proof. Taking the modulus of (11) and using (13) and (3), we have

$$
|\tau(x ; \alpha, \beta)|=\left|\int_{a}^{b} P(x, t) f^{\prime \prime}(t) d t\right| \leq \int_{a}^{b}|P(x, t)|\left|f^{\prime \prime}(t)\right| d t .
$$

Therefore, for $f^{\prime \prime} \in L_{\infty}[a, b]$, we obtain

$$
|\tau(x ; \alpha, \beta)| \leq\left\|f^{\prime \prime}\right\|_{\infty} \int_{a}^{b}|P(x, t)| d t .
$$

Now let us observe that

$$
\begin{aligned}
& \int_{a}^{b}|P(x, t)| d t \\
&=\frac{\alpha}{(\alpha+\beta)} \frac{1}{x-a} \int_{a}^{x} \frac{(t-a)^{2}}{2} d t \\
&+\frac{\beta}{(\alpha+\beta)} \frac{1}{b-x} \int_{x}^{b} \frac{(t-b)^{2}}{2} d t \\
&= \frac{\alpha}{(\alpha+\beta)} \frac{1}{x-a} \frac{(x-a)^{3}}{6} \\
&+\frac{\beta}{(\alpha+\beta)} \frac{1}{b-x} \frac{(b-x)^{3}}{6} \\
&= \frac{\alpha}{(\alpha+\beta)} \frac{(x-a)^{2}}{6}+\frac{\beta}{(\alpha+\beta)} \frac{(b-x)^{2}}{6} \\
&= \frac{1}{6(\alpha+\beta)}\left[\alpha(x-a)^{2}+\beta(b-x)^{2}\right] .
\end{aligned}
$$

Hence, the first inequality is obtained:

$$
|\tau(x ; \alpha, \beta)| \leq\left[\alpha(x-a)^{2}+\beta(b-x)^{2}\right] \frac{1}{6(\alpha+\beta)}\left\|f^{\prime \prime}\right\|_{\infty} .
$$

Further, using Hölder's integral inequality, from (15), we have for $f^{\prime \prime} \in L_{p}[a, b], p>1$,

$$
|\tau(x ; \alpha, \beta)| \leq\left\|f^{\prime \prime}\right\|_{p}\left(\int_{a}^{b}|P(x, t)|^{q} d t\right)^{1 / q},
$$

where $(1 / p)+(1 / q)=1$. Now

$$
\begin{aligned}
(\alpha+\beta) & \left(\int_{a}^{b}|P(x, t)|^{q} d t\right)^{1 / q} \\
= & {\left[\frac{\alpha^{q}}{2^{q}(x-a)^{q}} \int_{a}^{x}(t-a)^{2 q} d t\right.} \\
& \left.+\frac{\beta^{q}}{2^{q}(b-x)^{q}} \int_{x}^{b}(b-t)^{2 q} d t\right]^{1 / q} \\
= & \frac{1}{2(2 q+1)^{1 / q}} \\
& \times\left[\alpha^{q}(x-a)^{q+1}+\beta^{q}(b-x)^{q+1}\right]^{1 / q} .
\end{aligned}
$$


Hence, the second inequality is obtained as below:

$$
\begin{aligned}
|\tau(x ; \alpha, \beta)| \leq & \frac{1}{2(2 q+1)^{1 / q}(\alpha+\beta)} \\
& \times\left[\alpha^{q}(x-a)^{q+1}+\beta^{q}(b-x)^{q+1}\right]^{1 / q}\left\|f^{\prime \prime}\right\|_{p} .
\end{aligned}
$$

Finally, for $f^{\prime \prime} \in L_{1}[a, b]$, using (10), we have the following from (15). Consider

$$
|\tau(x ; \alpha, \beta)| \leq \sup _{t \in[a, b]}|P(x, t)|\left\|f^{\prime \prime}\right\|_{1}
$$

where

$$
\begin{aligned}
(\alpha+\beta) \sup _{t \in[a, b]}|P(x, t)|= & \max \left\{\frac{\alpha(x-a)}{2}, \frac{\beta(b-x)}{2}\right\} \\
= & \frac{\alpha(x-a)+\beta(b-x)}{4} \\
& +\left|\frac{\alpha(x-a)-\beta(b-x)}{4}\right| .
\end{aligned}
$$

This gives us the last inequality as below:

$$
\begin{aligned}
|\tau(x ; \alpha, \beta)| \leq & (\alpha(x-a)+\beta(b-x) \\
& +|\alpha(x-a)-\beta(b-x)|) \\
& \times \frac{\left\|f^{\prime \prime}\right\|_{1}}{4(\alpha+\beta)} .
\end{aligned}
$$

This completes the proof of the theorem.

Remark 5. We may write

$\alpha M(f ; a, x)+\beta M(f ; x, b)$

$$
\begin{aligned}
& =\alpha M(f ; a, x)+\frac{\beta}{b-x}\left(\int_{a}^{b} f(u) d u-\int_{a}^{x} f(u) d u\right) \\
& =\alpha M(f ; a, x)-\frac{\beta}{b-x} \int_{a}^{x} f(u) d u+\frac{\beta}{b-x} \int_{a}^{b} f(u) d u \\
& =(\alpha+\beta-\beta \sigma(x)) M(f ; a, x)+\beta \sigma(x) M(f ; a, b),
\end{aligned}
$$

where

$$
\frac{b-a}{b-x}=\sigma(x)
$$

Thus, from (13),

$$
\begin{aligned}
\tau(x ; \alpha, \beta)= & \frac{1}{2(\alpha+\beta)}[\alpha(x-a)-\beta(b-x)] f^{\prime}(x)-f(x) \\
+ & {\left[\left(1-\frac{\beta}{\alpha+\beta} \sigma(x)\right) M(f ; a, x)\right.} \\
& \left.+\frac{\beta}{\alpha+\beta} \sigma(x) M(f ; a, b)\right],
\end{aligned}
$$

so that, for fixed $[a, b], M(f ; a, b)$ is also fixed.
Corollary 6. Let the condition of Theorem 4 hold and $\alpha=\beta$; then,

$$
\begin{aligned}
& \mid \frac{1}{4}[(x-a)-(b-x)] f^{\prime}(x)-f(x) \\
& +\frac{1}{2}[M(f ; a, x)+M(f ; x, b)] \mid \\
& \quad \leq\left\{\begin{array}{l}
{\left[(x-a)^{2}+(b-x)^{2}\right] \frac{\left\|f^{\prime \prime}\right\|_{\infty}}{12},} \\
f^{\prime \prime} \in L_{\infty}[a, b], \\
\frac{1}{(2 q+1)^{1 / q}}\left[(x-a)^{q+1}+(b-x)^{q+1}\right] \frac{1 / q}{f^{\prime \prime} \in L_{p}[a, b], p>1, \frac{1}{q}+\frac{1}{p}=1} \\
\left(b-a+2\left|x-\frac{a+b}{2}\right|\right) \frac{\left\|f^{\prime \prime}\right\|_{1}}{8}, \\
f^{\prime \prime} \in L_{\infty}[a, b] .
\end{array}\right.
\end{aligned}
$$

Proof. The proof of the above corollary is a straightforward exercise after putting $\alpha=\beta$ in (14).

Corollary 7. Let the conditions of Theorem 4 hold and $x=$ $(a+b) / 2$. Then,

$$
\begin{aligned}
& \mid \frac{b-a}{4(\alpha+\beta)}(\alpha-\beta) f^{\prime}\left(\frac{a+b}{2}\right)-f\left(\frac{a+b}{2}\right) \\
& +\frac{2}{(b-a)(\alpha+\beta)} \\
& \times\left(\alpha \int_{a}^{(a+b) / 2} f(t) d t+\beta \int_{(a+b) / 2}^{b} f(t) d t\right) \mid \\
& \leq\left\{\begin{array}{l}
\frac{(b-a)^{2}}{24}\left\|f^{\prime \prime}\right\|_{\infty}, f^{\prime \prime} \in L_{\infty}[a, b], \\
\left(\frac{b-a}{2}\right)^{1+(1 / q)} \frac{1}{(2 q+1)^{1 / q}} \\
\times\left(\alpha^{q}+\beta^{q}\right)^{1 / q} \frac{\left\|f^{\prime \prime}\right\|_{p}}{2(\alpha+\beta)}, \quad f^{\prime \prime} \in L_{p}[a, b], \\
(b-a)\left(1+\frac{|\alpha-\beta|}{\alpha+\beta}\right) \frac{\left\|f^{\prime \prime}\right\|_{1}}{8}, \quad f^{\prime \prime} \in L_{1}[a, b] .
\end{array}, \frac{1}{p}=1,\right.
\end{aligned}
$$

Proof. Placing $x=(a+b) / 2$ in (13) and (14) produces the results stated in (29). 
Corollary 8. If (28) is evaluated at the midpoint, then

$$
\begin{aligned}
& \left|f\left(\frac{a+b}{2}\right)-\frac{1}{(b-a)} \int_{a}^{b} f(t) d t\right| \\
& \leq\left\{\begin{array}{c}
\frac{(b-a)^{2}}{24}\left\|f^{\prime \prime}\right\|_{\infty}, \quad f^{\prime \prime} \in L_{\infty}[a, b], \\
(b-a)^{1+(1 / q)} \frac{\left\|f^{\prime \prime}\right\|_{p}}{8(2 q+1)^{1 / q}}, \\
f^{\prime \prime} \in L_{p}[a, b], \\
p>1, \frac{1}{q}+\frac{1}{p}=1, \\
(b-a) \frac{\left\|f^{\prime \prime}\right\|_{1}}{8}, \quad f^{\prime \prime} \in L_{1}[a, b] .
\end{array}\right.
\end{aligned}
$$

The above result can also be obtained by taking $\alpha=\beta$ in (29) or equivalently $\alpha=\beta$ and $x=(a+b) / 2$ in (14).

\section{Perturbed Results}

In 1882, Čebyŝev [20] gave the following inequality:

$$
|T(f, g)| \leq \frac{1}{12}(b-a)^{2}\left\|f^{\prime}\right\|_{\infty}\left\|g^{\prime}\right\|_{\infty},
$$

where $f, g:[a, b] \rightarrow \mathbb{R}$ are absolutely continuous functions, which have bounded first derivatives, and

$$
\begin{aligned}
T(f, g):= & \frac{1}{b-a} \int_{a}^{b} f(x) g(x) d x \\
& -\left(\frac{1}{b-a} \int_{a}^{b} f(x) d x\right)\left(\frac{1}{b-a} \int_{a}^{b} g(x) d x\right) \\
= & M(f g ; a, b)-M(f ; a, b) M(g ; a, b) .
\end{aligned}
$$

In 1935, Grüss [21] proved the following inequality:

$$
\begin{aligned}
& \mid \frac{1}{b-a} \int_{a}^{b} f(x) g(x) d x \\
& -\frac{1}{b-a} \int_{a}^{b} f(x) d x \frac{1}{b-a} \int_{a}^{b} g(x) d x \mid \\
& \quad \leq \frac{1}{4}(\Phi-\varphi)(\Gamma-\gamma),
\end{aligned}
$$

provided that $f$ and $g$ are two integrable functions on $[a, b]$ and satisfy the condition

$$
\varphi \leq f(x) \leq \Phi, \quad \gamma \leq g(x) \leq \Gamma, \quad \text { for all } x \in[a, b] .
$$

The constant $1 / 4$ is the best possible. The perturbed version of the results of Theorem 4 can be obtained by using Grüss type results involving the Čebyŝev functional

$$
T(f, g)=M(f g ; a, b)-M(f ; a, b) M(g ; a, b),
$$

where $M$ is the integral mean defined in (3). Let

$$
\begin{aligned}
& \kappa:=\frac{f^{\prime}(b)-f^{\prime}(a)}{b-a}, \\
& N^{2}(x):=\left(\left(\frac{\alpha}{\alpha+\beta}\right)^{2} \frac{(x-a)^{3}}{20}+\left(\frac{\beta}{\alpha+\beta}\right)^{2} \frac{(b-x)^{3}}{20}\right) \frac{1}{b-a} \\
&-\left(\frac{1}{6(b-a)(\alpha+\beta)}\left[\alpha(x-a)^{2}+\beta(b-x)^{2}\right]\right)^{2} .
\end{aligned}
$$

Theorem 9. Let $f:[a, b] \rightarrow \mathbb{R}$ be a two times differentiable function, and $\alpha, \beta$ are nonnegative real numbers. Then,

$$
\begin{aligned}
\left|\tau(x ; \alpha, \beta)-\frac{1}{(\alpha+\beta)}\left[\alpha(x-a)^{2}+\beta(b-x)^{2}\right] \frac{\kappa}{6}\right| & \leq(b-a) N(x)\left[\frac{1}{b-a}\left\|f^{\prime \prime}\right\|_{2}^{2}-\kappa^{2}\right]^{1 / 2} \\
& \leq \frac{(b-a)(\Gamma-\gamma)}{2(\alpha+\beta)} \max \left\{\frac{\alpha(x-a)}{2}, \frac{\beta(b-x)}{2}\right\},
\end{aligned}
$$

where $\tau(x ; \alpha, \beta)$ is as given by (13).

Proof. Associating $f(t)$ with $P(x, t)$ and $g(t)$ with $f^{\prime \prime}(t)$, we obtain

$$
\begin{aligned}
& T\left(P(x, \cdot), f^{\prime \prime}(\cdot) ; a, b\right) \\
&= M\left(P(x, \cdot) f^{\prime \prime}(\cdot) ; a, b\right) \\
&-M(P(x, \cdot) ; a, b) M\left(f^{\prime \prime}(\cdot) ; a, b\right) .
\end{aligned}
$$

Now using identity (11),

$$
\begin{aligned}
& (b-a) T\left(P(x, \cdot), f^{\prime \prime}(\cdot) ; a, b\right) \\
& =\tau(x ; \alpha, \beta)-(b-a) M(P(x, \cdot) ; a, b) \kappa,
\end{aligned}
$$

where $\kappa$ is the secant slope of $f^{\prime}$ over $[a, b]$ as given in (36). Now, from (11) and (32),

$$
\begin{aligned}
(b-a) & M(P(x, \cdot) ; a, b) \\
= & \int_{a}^{b} P(x, t) d t \\
= & \frac{\alpha}{(\alpha+\beta)} \frac{1}{x-a} \int_{a}^{x} \frac{(t-a)^{2}}{2} d t \\
& +\frac{\beta}{(\alpha+\beta)} \frac{1}{b-x} \int_{x}^{b} \frac{(t-b)^{2}}{2} d t \\
= & \frac{1}{6(\alpha+\beta)}\left[\alpha(x-a)^{2}+\beta(b-x)^{2}\right] .
\end{aligned}
$$

Now, combining (41) with (37), the left-hand side of (38) is obtained. 
Let $f, g:[a, b] \rightarrow \mathbb{R}$ and $f g:[a, b] \rightarrow \mathbb{R}$ be integrable on $[a, b]$; then $[3]$,

$$
\begin{aligned}
|T(f, g)| & \leq T^{1 / 2}(f, f) T^{1 / 2}(g, g) \quad\left(f, g \in L_{2}[a, b]\right) \\
& \leq \frac{(\Gamma-\gamma)}{2} T^{1 / 2}(f, f) \quad(\gamma \leq g(x) \leq \Gamma, t \in[a, b]) \\
& \leq \frac{1}{4}(\Phi-\varphi)(\Gamma-\gamma) \quad(\varphi \leq f(x) \leq \Phi, t \in[a, b]) .
\end{aligned}
$$

Also, note that

$$
\begin{aligned}
0 & \leq T^{1 / 2}\left(f^{\prime \prime}(\cdot), f^{\prime \prime}(\cdot)\right) \\
& =\left[M\left(f^{\prime \prime}(\cdot)^{2} ; a, b\right)-M^{2}\left(f^{\prime \prime}(\cdot) ; a, b\right)\right]^{1 / 2} \\
& =\left[\frac{1}{b-a} \int_{a}^{b}\left|f^{\prime \prime}(t)\right|^{2} d t-\left(\frac{\int_{a}^{b} f^{\prime \prime}(t) d t}{b-a}\right)^{2}\right]^{1 / 2} \\
& =\left[\frac{1}{b-a}\left\|f^{\prime \prime}\right\|_{2}^{2}-\kappa^{2}\right]^{1 / 2} \\
& \leq \frac{(\Gamma-\gamma)}{2},
\end{aligned}
$$

where $\gamma \leq f^{\prime \prime}(t) \leq \Gamma, t \in[a, b]$. Now, for the bounds on (40), we have to determine $T^{1 / 2}(P(x, \cdot), P(x, \cdot))$ and $\phi$ and $\Phi$ such that $\varphi \leq P(x, \cdot) \leq \Phi$.

Now from (10), the definition of $P(x, t)$, we have

$$
T(P(x, \cdot), P(x, \cdot))=M\left(P^{2}(x, \cdot) ; a, b\right)-M^{2}(P(x, \cdot) ; a, b) .
$$

From (41) we obtain

$$
\begin{aligned}
& M(P(x, \cdot) ; a, b) \frac{1}{6(b-a)(\alpha+\beta)}\left[\alpha(x-a)^{2}+\beta(b-x)^{2}\right] \\
&(b-a) M\left(P^{2}(x, \cdot) ; a, b\right) \\
&=\left(\frac{\alpha}{\alpha+\beta}\right)^{2} \frac{1}{4(x-a)^{2}} \int_{a}^{x}(t-a)^{4} d t \\
& \quad+\left(\frac{\beta}{\alpha+\beta}\right)^{2} \frac{1}{4(b-x)^{2}} \int_{x}^{b}(t-b)^{4} d t \\
&=\left(\frac{\alpha}{\alpha+\beta}\right)^{2} \frac{(x-a)^{3}}{20}+\left(\frac{\beta}{\alpha+\beta}\right)^{2} \frac{(b-x)^{3}}{20} .
\end{aligned}
$$

Thus, substituting the above results into (44) gives

$$
0 \leq N(x):=T^{1 / 2}(P(x, \cdot), P(x, \cdot))
$$

which is given explicitly by (37). Combining (40), (43), and (44) gives, from the first inequality in (42), the first inequality in (38). Now utilizing the inequality in (43) produces the second result in (38). Further, it may be noticed from the definition of $P(x, t)$ in (10) that, for $\alpha, \beta \geq 0$ it gives, for

$$
\Phi=\sup _{t \in[a, b]} P(x, t), \quad \varphi=\inf _{t \in[a, b]} P(x, t),
$$

the values

$$
\Phi=\frac{1}{(\alpha+\beta)} \max \left\{\frac{\alpha(x-a)}{2}, \frac{\beta(b-x)}{2}\right\}, \quad \varphi=0 .
$$

\section{An Application to the Cumulative Distribution Function}

Let $X \in[a, b]$ be a random variable with the cumulative distributive function

$$
F(x)=P_{r}(X \leq x)=\int_{a}^{x} f(u) d u,
$$

where $f$ is the probability density function. In particular,

$$
\int_{a}^{b} f(u) d u=1
$$

The following theorem holds.

Theorem 10. Let $X$ and $F$ be as above; then,

$$
\begin{aligned}
& \mid \frac{1}{2}(x-a)(b-x)[\alpha(x-a)-\beta(b-x)] \\
& \quad \times f^{\prime}(x)+[\alpha(b-x)-\beta(x-a)] F(x) \\
& \quad-(x-a)[(\alpha+\beta)(b-x) f(x)-\beta] \mid
\end{aligned}
$$

$$
\left\{\begin{array}{l}
{\left[\alpha(x-a)^{3}(b-x)+\beta(b-x)^{3}(x-a)\right]} \\
\times \frac{\left\|f^{\prime \prime}\right\|_{\infty}}{6}, \quad f^{\prime \prime} \in L_{\infty}[a, b] \\
\frac{1}{(2 q+1)^{1 / q}}\left[\alpha^{q}(b-x)(x-a)^{q+2}\right. \\
\left.+\beta^{q}(x-a)(b-x)^{q+2}\right]^{1 / q} \frac{\left\|f^{\prime \prime}\right\|_{p}}{2}, \\
f^{\prime \prime} \in L_{p}[a, b], \\
p>1, \frac{1}{q}+\frac{1}{p}=1, \\
(b-x)(x-a)(\alpha(x-a)+\beta(b-x) \\
+|\alpha(x-a)-\beta(b-x)|) \frac{\left\|f^{\prime \prime}\right\|_{1}}{4}, \\
f^{\prime \prime} \in L_{1}[a, b] .
\end{array}\right.
$$


Proof. From (13), and by using the definition of probability density function, we have

$$
\begin{aligned}
\tau(x ; \alpha, \beta) & \\
= & \frac{1}{2(\alpha+\beta)}[\alpha(x-a)-\beta(b-x)] f^{\prime}(x)-f(x) \\
& +\frac{1}{\alpha+\beta}[\alpha M(f ; a, x)+\beta M(f ; x, b)] \\
= & \frac{1}{2(\alpha+\beta)}[\alpha(x-a)-\beta(b-x)] f^{\prime}(x)-f(x) \\
& +\frac{1}{\alpha+\beta}\left\{\left[\frac{\alpha(b-x)-\beta(x-a)}{(x-a)(b-x)}\right] F(x)+\frac{\beta}{(b-x)}\right\}
\end{aligned}
$$

or

$$
\begin{aligned}
(\alpha+\beta) & (x-a)(b-x) \tau(x ; \alpha, \beta) \\
= & \frac{(x-a)(b-x)}{2}[\alpha(x-a)-\beta(b-x)] f^{\prime}(x) \\
& -(\alpha+\beta)(x-a)(b-x) f(x) \\
& +\{[\alpha(b-x)-\beta(x-a)] F(x)+\beta(x-a)\} .
\end{aligned}
$$

Now using (14) and (53), we get our required result (51). result.

Putting $\alpha=\beta=1 / 2$ in Theorem 10 gives the following

Corollary 11. Let $X$ be a random variable with the cumulative distributive function $F(x)$ and the probability density function $f(x)$. Then,

$$
\begin{aligned}
& \mid\left(x-\frac{a+b}{2}\right)\left[\frac{1}{2}(x-a)(b-x) f^{\prime}(x)-F(x)\right] \\
& -(x-a)\left[(b-x) f(x)-\frac{1}{2}\right] \mid \\
& \leq\left\{\begin{array}{c}
{\left[(x-a)^{3}(b-x)+(b-x)^{3}(x-a)\right] \frac{\left\|f^{\prime \prime}\right\|_{\infty}}{12},} \\
f^{\prime \prime} \in L_{\infty}[a, b], \\
\frac{1}{(2 q+1)^{1 / q}} \\
\times\left[(b-x)(x-a)^{q+2}+(x-a)(b-x)^{q+2}\right]^{1 / q} \\
\quad \times \frac{\left\|f^{\prime \prime}\right\|_{p}}{4}, \quad f^{\prime \prime} \in L_{p}[a, b], p>1, \frac{1}{q}+\frac{1}{p}=1, \\
(b-x)(x-a)\left(b-a+\left|x-\frac{a+b}{2}\right|\right) \frac{\left\|f^{\prime \prime}\right\|_{1}}{8}, \\
f^{\prime \prime} \in L_{1}[a, b] .
\end{array}\right.
\end{aligned}
$$

Remark 12. The above result allows the approximation of $F(x)$ in terms of $f(x)$. The approximation of

$$
R(x)=1-F(x)
$$

could also be obtained by a simple substitution. $R(x)$ is of importance in reliability theory, where $f(x)$ is the probability density function of failure.

Remark 13. We put $\beta=0$ in (51), assuming that $\alpha \neq 0$, to obtain

$$
\begin{aligned}
& \left|F(x)+(x-a)\left[\frac{1}{2}(x-a) f^{\prime}(x)-f(x)\right]\right| \\
& \leq\left\{\begin{array}{l}
(x-a)^{3} \frac{\left\|f^{\prime \prime}\right\|_{\infty}}{6}, \quad f^{\prime \prime} \in L_{\infty}[a, b], \\
\frac{1}{(2 q+1)^{1 / q}}(b-x)^{(1 / q)-1}(x-a)^{1+(2 / q)} \frac{\left\|f^{\prime \prime}\right\|_{p}}{2}, \\
f^{\prime \prime} \in L_{p}[a, b], \\
\quad p>1, \frac{1}{q}+\frac{1}{p}=1, \\
(x-a)^{2} \frac{\left\|f^{\prime \prime}\right\|_{1}}{2}, \\
f^{\prime \prime} \in L_{1}[a, b] .
\end{array}\right.
\end{aligned}
$$

Further we note that

$$
\int_{a}^{b} F(u) d u=\left.u F(u)\right|_{a} ^{b}-\int_{a}^{b} x f(x) d x=b-E(X) .
$$

\section{Conclusions}

In this paper, we obtained bounds for the deviation of a function from a combination of integral means over the end intervals covering the entire interval in terms of the $L_{p}$ norms at the second derivative. The obtained results are applied to approximate the cumulative distribution function. Our results further extend previous inequalities developed in $[3,14-17]$. Some perturbed results with the help of Čebyŝev and Grüss inequalities are also obtained.

\section{Conflict of Interests}

The authors declare that there is no conflict of interests regarding the publication of this paper.

\section{Acknowledgment}

The authors would like to thank Professor Elena berdysheva for her useful suggestions which improved the presentation of the paper.

\section{References}

[1] A. Ostrowski, "Uber die Absolutabweichung einer differenzierbaren Funktionen von ihren In-tegralimittelwert," Commentarii Mathematici Helvetici, vol. 10, pp. 226-227, 1938. 
[2] G. V. Milovanović and J. E. Pecarić, "On generalization of the inequality of A. Ostrowski and some related applications," Univerzitet u Beogradu Publikacije ElektrotehnIckog Fakulteta, Serija Matematika i Fizika, vol. 544-576, pp. 155-158, 1976.

[3] P. Cerone, "A new Ostrowski type inequality involving integral means over end intervals," Tamkang Journal of Mathematics, vol. 33, no. 2, 2002.

[4] X. L. Cheng, "Improvement of some Ostrowski-Grüss type inequalities," Computers \& Mathematics with Applications, vol. 42, pp. 109-114, 2001.

[5] S. S. Dragomir and N. S. Barnett, "An Ostrowski type inequality for mappings whose sec- ond derivatives are bounded and applications RGMIA Research Report Collection," Vaal University of Technology, vol. 1, pp. 67-76, 1999.

[6] A. Sofo and S. S. Dragomir, "An inequality of Ostrowski type for twice differentiable mappings in term of the $L_{p}$ norm and applications," Soochow Journal of Mathematics, vol. 27, no. 1, pp. 97-111, 2001.

[7] G. V. Milovanović, "On some integral inequalities," Univerzitet u Beogradu Publikacije ElektrotehnIckog Fakulteta, Serija Matematika i Fizika, no. 498-541, pp. 119-124, 1975.

[8] G. V. Milovanović and I. Z. Milovanović, "A generalization of certain results given by A. Os- trowski and A. Lupas," Univerzitet u Beogradu PubiIkacije ElektrotehnIckog Fakulteta, Serija Matematika i Fizika, no. 634-677, pp. 62-69, 1979.

[9] S. Hussain and A. Qayyum, "A generalized Ostrowski-Grüss type inequality for bounded differentiable mappings and its applications," Journal of Inequalities and Applications, vol. 2013, article 1, 2013.

[10] A. Qayyum and S. Hussain, "A new generalized Ostrowski Grüss type inequality and applications," Applied Mathematics Letters, vol. 25, pp. 1875-1880, 2012.

[11] J. E. Pecarić, "On the Čebyŝev inequality," Buletinul Stiintific si Tehnic al Institutului Politehnic "Traian Vuia” Timişoara, vol. 25, no. 39, pp. 5-9, 1980.

[12] Z. Liu, "Some companions of an Ostrowski type inequality and applications," Journal of Inequalities in Pure and Applied Mathematics, vol. 10, no. 2, pp. 1-12, 2009.

[13] W. Liu, Y. Jiang, and A. Tuna, "A unified generalization of some quadrature rules and error bounds," Applied Mathematics and Computation, vol. 219, pp. 4765-4774, 2013.

[14] S. S. Dragomir and S. Wang, "An inequality Ostrowski-Grüss type and its applications to the estimation of error bounds for some special means and for some numerical quadrature rules," Computers \& Mathematics with Applications, vol. 33, pp. 15-22, 1997.

[15] S. S. Dragomir and S. Wang, "A new inequality Ostrowski's type in $L_{p}$ norm," Indian Journal of Mathematics, vol. 40, pp. 299304, 1998

[16] S. S. Dragomir and S. Wang, "A new inequality Ostrowski.s type in $L_{1}$ norm and applications to some special means and some numerical quadrature rules," Tamkang Journal of Mathematics, vol. 28, pp. 239-244, 1997.

[17] S. S. Dragomir and S. Wang, "Applications of Ostrowski's inequality to the estimation of error bounds for some special means and for some numerical quadrature rules," Applied Mathematics Letters, vol. 11, no. 1, pp. 105-109, 1998.

[18] D. S. Mitrinović, J. E. Pecarić, and A. M. Fink, Inequalities for Functions and Their Integrals and Derivatives, Kluwer Academic Publishers, Dordrecht, The Netherlands, 1994.
[19] B. G. Pachpatte, "On Čebyŝev-Grüss type inequalities via Pecaric's extention of the Mont- gomery identity," Journal of Inequalities in Pure and Applied Mathematics, vol. 7, no. 1, article 108, 2006.

[20] P. L. Čebyŝev, "Sur less expressions approximatives des integrales definies par les autres prises entre les memes limites," Proc. Math. Soc. Charkov, vol. 2, pp. 93-98, 1882.

[21] G. Grüss, "Über das Maximum des absoluten Betrages von $1 /(b-a) \int_{a}^{b} f(x) g(x) d x-1 /(b-a)^{2} \int_{a}^{b} f(x) d x \int_{a}^{b} g(x) d x$, Mathematische Zeitschrift, vol. 39, no. 1, pp. 215-226, 1935. 


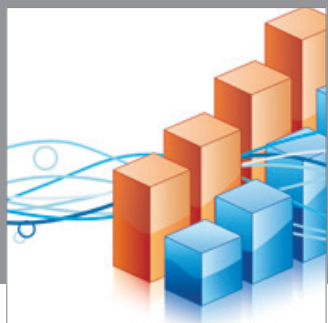

Advances in

Operations Research

mansans

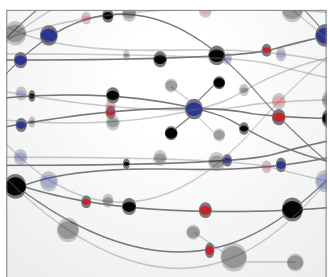

The Scientific World Journal
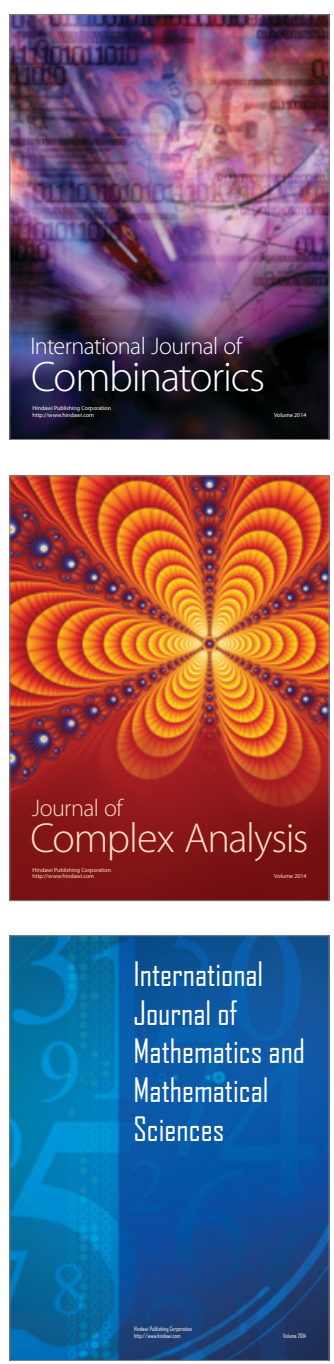
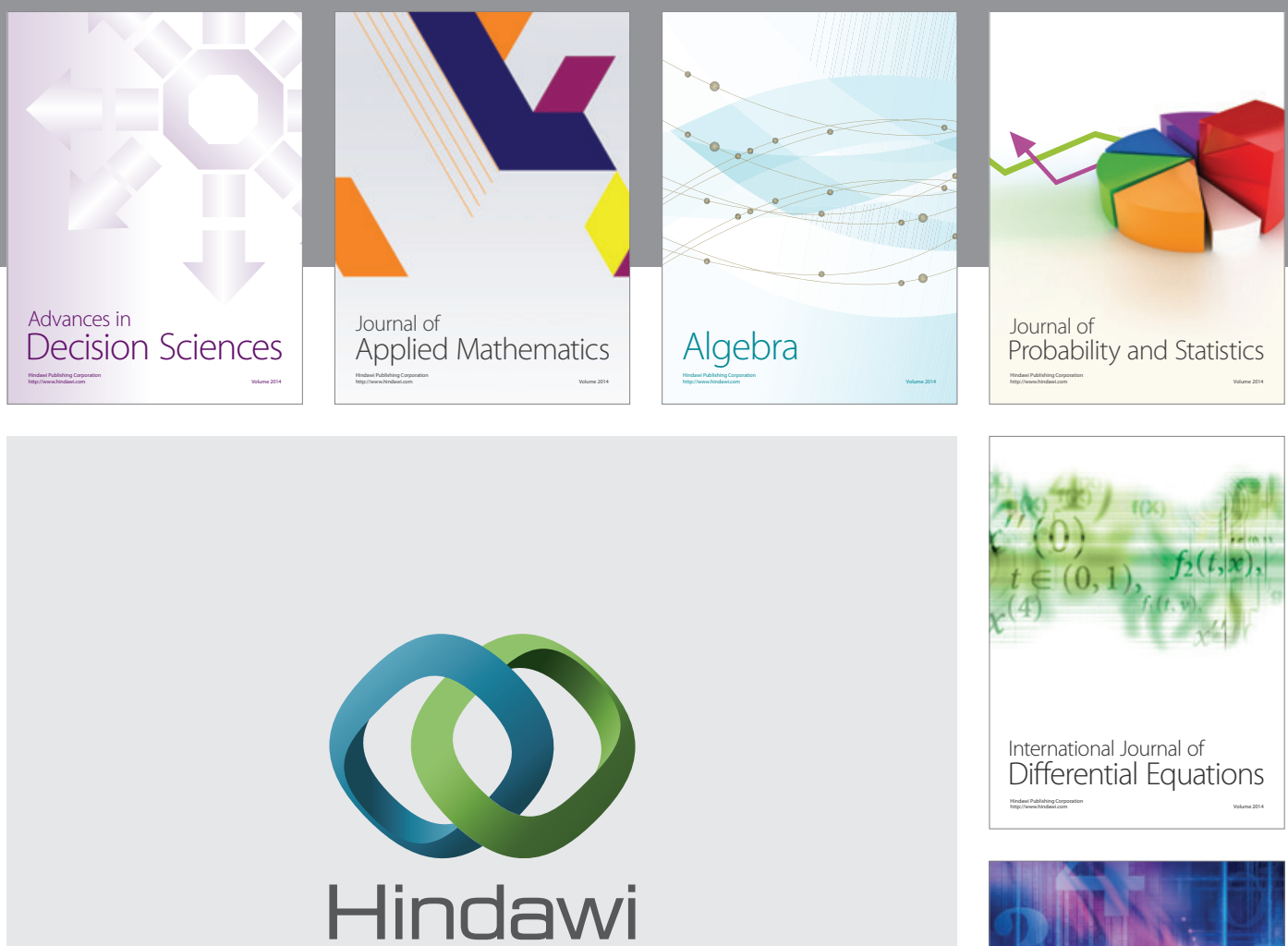

Submit your manuscripts at http://www.hindawi.com
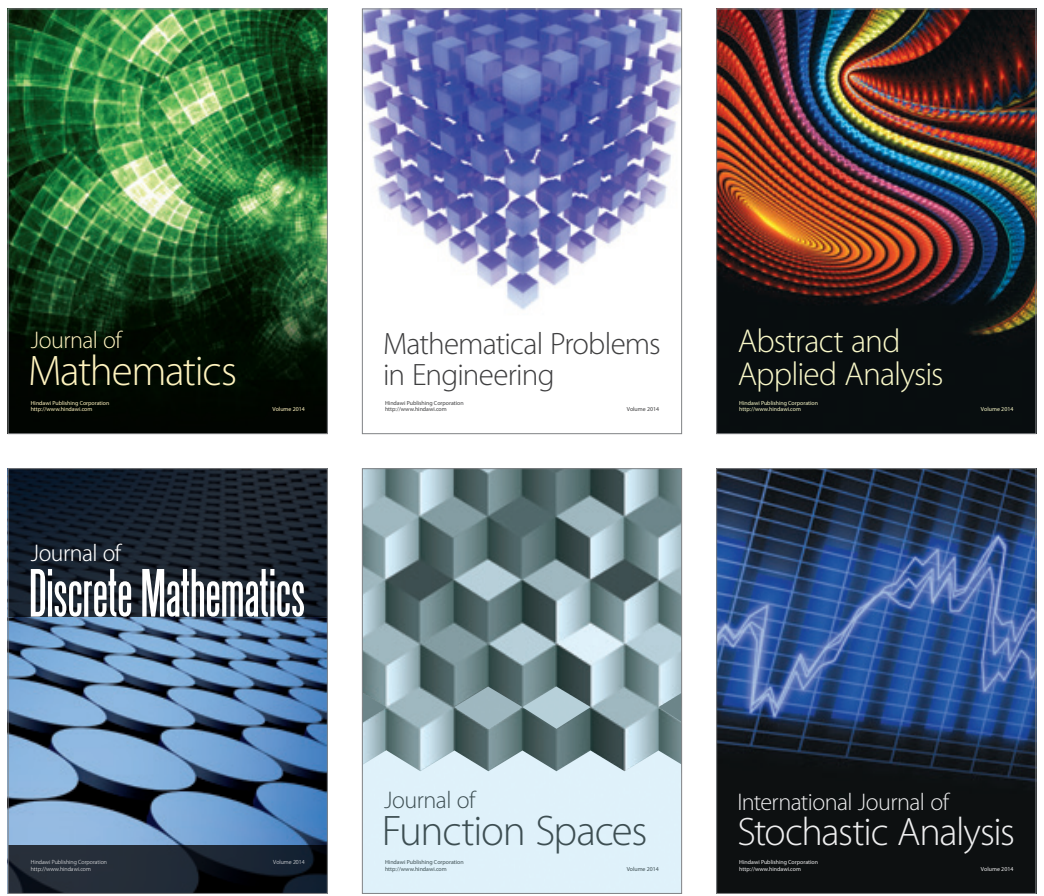

Journal of

Function Spaces

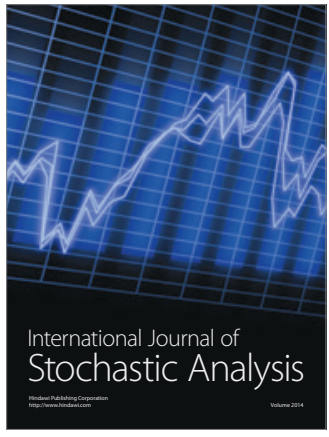

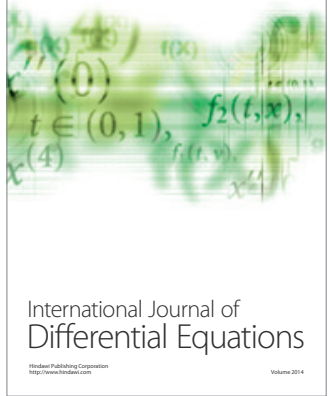
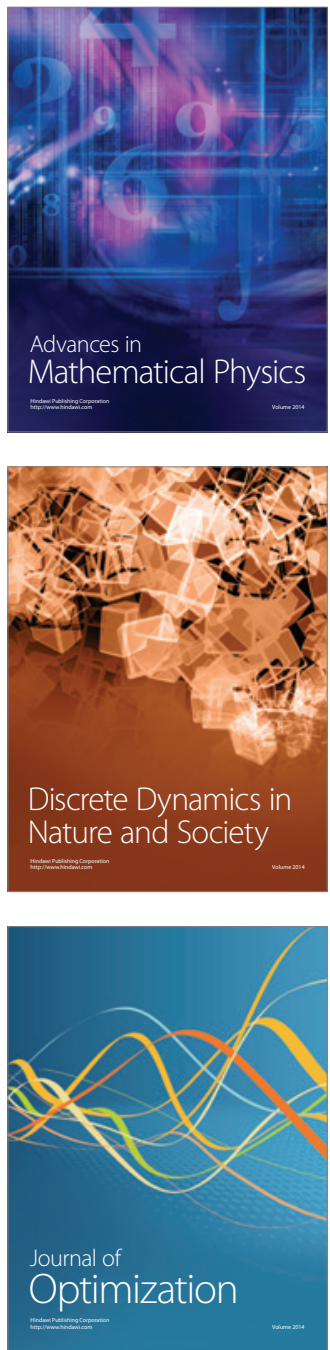